\title{
Clinical and functional profile of 6-12-year-old children with attention deficit hyperactivity disorder referred to a tertiary care center in South India
}

\author{
Gupta A. ${ }^{1 *}$, George B. ${ }^{2}$, Nair M. ${ }^{3}$, Leena $\mathrm{ML}^{4}$, Bhaskaran D. ${ }^{5}$ \\ DOI: https://doi.org/10.17511/ijmrr.2020.i04.08 \\ 1* Arpita Gupta, IAP Fellow in Development and Behaviour Pediatrics, Child Development Centre, Thiruvananthapuram, Kerala, India. \\ 2 Babu George, Director, Child Development Centre and Medical College, Thiruvananthapuram, Kerala, India. \\ 3 MKC Nair, Emeritus Professor in Developmental, Behavioral and Adolescent Pediatrics, Child Development Centre and Medical College, \\ Thiruvananthapuram, Kerala, India. \\ ${ }^{4}$ Leena ML, Senior Research Coordinator, Child Development Centre and Medical College, Thiruvananthapuram, Kerala, India. \\ 5 Deepa Bhaskaran, Assistant Professor of Developmental Pediatrics, Child Development Centre and Medical College, Thiruvananthapuram, \\ Kerala, India.
}

Objective: To describe the clinical, socio-demographic, and functional profile of children with Attention Deficit Hyperactivity Disorder (ADHD) referred to a tertiary care center in Kerala, India. Methods: A retrospective descriptive study was conducted from records of developmental evaluation clinic over a period of one year. All-consecutive cases the first time diagnosed as ADHD were enrolled. Autism Spectrum Disorder, genetic disorders, and children with sensory impairments were excluded. Results: ADHD prevalence in a clinically referred sample was $12.7 \%$. Boy to girl ratio was $6: 1$. The mean age of presentation was 8.2 years (SD 6.09). The most common presenting symptom was hyperactivity and behavioral problems followed by poor scholastic performance and poor memory. The functional status assessment showed major concerns in all six domains Inattention, Hyperactivity, Learning Problem, Executive Functioning, Aggression, and Peer relation, in the majority of children. Conclusion: Course of childhood ADHD shows a consistent clinical and functional pattern. Early diagnosis and quantification of difficulties at the outset is suggested, which can help in providing early intervention and is likely to improve long-term outcome in these children.

Keywords: ADHD, Clinical profile, Functional profile, Primary school children

Corresponding Author

Arpita Gupta, IAP Fellow in Development and Behaviour Pediatrics, , Child Development Centre, Thiruvananthapuram, Kerala, India. Email: arpita1517@gmail.com

\section{How to Cite this Article}

Gupta A, George B, Nair MKC, Leena ML, Bhaskaran D. Clinical and functional profile of 6-12-year-old children with attention deficit hyperactivity disorder referred to a tertiary care center in South India. Int J Med Res Rev. 2020;8(4):331-337.

\section{Available From}

https://ijmrr.medresearch.in/index.php/ijmrr/article/ view/1208
To Browse

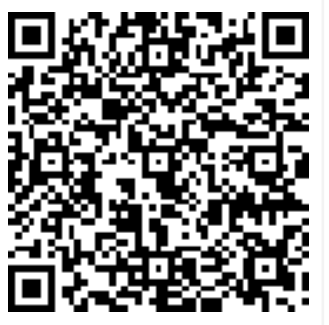




\section{Introduction}

Attention Deficit Hyperactivity Disorder (ADHD) is the most common neurodevelopmental disorder of childhood and can profoundly affect the academic achievement, functional well-being, and social interactions of children of all age groups as well as adults [1]. According to DSM-5, ADHD is a persistent pattern of Inattention and/ or Hyperactivity- Impulsivity that interferes with functioning or development [2]. Meta-regression analysis has estimated global ADHD prevalence in children and adolescents between 5.3\%-7\% [3,4]. In India, according to a study done in primary school children in Tamil Nadu, the prevalence of ADHD is $11.32 \%$ [5]. Because of the high prevalence of ADHD in primary school children, more studies are required to describe associated problems and functional status of these children, especially in the Indian context. The present study is an attempt to describe the socio-demographic, clinical profile and functional status in primary school-aged children (6-12 years) with ADHD referred to as a tertiary care Centre in Kerala, India. Objectives of this study were

- To describe the clinical and socio-demographic profile of children with ADHD.

- To describe the functional status of the children.

- To identify any association between the functional and demographic profile of children with ADHD.

\section{Methods}

This study was conducted at the Child Development Centre (CDC), Kerala, a tertiary care center for clinical child development with a meticulous recordkeeping system. It was a retrospective descriptive study conducted from the records of children aged 6-12 years who attended CDC between July 2017 to June 2018 with various issues.

\section{Inclusion criteria}

All consecutive children, newly diagnosed as ADHD by DSM- 5 criteria were enrolled.

A sample of convenience was chosen. Per year around 500-525 children between the age group 612 year present to CDC with various issues out of which $10-15 \%$ are diagnosed with ADHD. In the present study, records of 51 children fulfilling inclusion and exclusion criteria were included. Children with comorbid conditions like Autism
Spectrum Disorder, known genetic disorders, and vision and hearing impairments were excluded. Experts including developmental therapists, Clinical psychologist, and Developmental Pediatrician assessed the children at the initial presentation, before starting medications and specific therapies and the data was collected in the records. Sociodemographic profile was based on gender and age of the child, area of residence, parental education, type of family, and socio-economic status. Clinical history was based on presenting symptoms, family history, and the developmental history of the child. Functional status was based on Conner's 3 Parent Scale, Intelligence Quotient (IQ), and Social Quotient (SQ). Conner's rating scale helps in quantifying the severity level in each domain (i.e. hyperactivity, inattention, learning problems, aggression, peer relation, and executive functioning). A t-score of $\geq 70$ indicates an extremely high level of concern in the domain, 6069 indicates more than a typical level of concern and $<60$ indicates a typical level of concern. Intelligence Quotient was assessed by Raven's Colored Progressive Matrices and Social Quotient by Vineland Social Maturity Scale.

The investigator accessed the data after due permission from the head of the institution and ethics committee.

Statistical analysis: Data was collected in an anonymous manner and analyzed by a statistician using SPSS software version 21.0. For the comparison of qualitative variables, the chi-square test was used. Linear regression was used to identify any association. P-value $<0.05$ was considered significant.

\section{Results}

A prevalence of $12.7 \%$ of ADHD was observed among the 6-12-year-old children referred to CDC for various issues.

Socio-demographic profile: Out of 51 children included in the study $44(86 \%)$ were boys and 7 $(14 \%)$ were girls, with a boy to girl ratio of $6: 1$. The mean age at presentation was 8.2 years (SD \pm 6.09). It was observed that $60 \%$ of children belonged to nuclear families. $100 \%$ of parents of the sample population were literate with at least primary education and overall maternal education was more as compared to father's education. The majority of children ( $70 \%)$ belonged to upper and upper-middle-class socioeconomic status according 
To Modified Kuppuswamy Scale. Around $66.6 \%$ of children lived in a rural area and $33 \%$ were from an urban background (Table 1 ).

Table-1: Socio-demographic profile.

\begin{tabular}{|c|c|c|}
\hline Characteristics & Number & Percentage \\
\hline \multicolumn{3}{|l|}{ Gender of children } \\
\hline Male & 44 & 86.3 \\
\hline Female & 7 & 13.7 \\
\hline \multicolumn{3}{|l|}{ Age of children } \\
\hline $6-8$ years & 37 & 72.5 \\
\hline $9-12$ years & 14 & 27.5 \\
\hline \multicolumn{3}{|l|}{ Education of mother } \\
\hline Illiterate & 0 & 0 \\
\hline Primary & 0 & 0 \\
\hline Middle school & 10 & 19.6 \\
\hline High school & 7 & 13.7 \\
\hline Graduate & 29 & 56.9 \\
\hline Professional & 5 & 9.8 \\
\hline \multicolumn{3}{|l|}{ Education of father } \\
\hline Illiterate & 0 & 0 \\
\hline Primary & 1 & 2.0 \\
\hline Middle school & 16 & 31.4 \\
\hline High school & 13 & 25.5 \\
\hline Graduate & 16 & 31.4 \\
\hline Professional & 5 & 9.8 \\
\hline \multicolumn{3}{|l|}{ Type of Family } \\
\hline Nuclear & 30 & 58.8 \\
\hline Extended & 20 & 39.2 \\
\hline Joint & 1 & 2.0 \\
\hline \multicolumn{3}{|l|}{ Place of Residence } \\
\hline Rural & 34 & 66.6 \\
\hline Urban & 17 & 33.3 \\
\hline \multicolumn{3}{|l|}{ Socioeconomic status } \\
\hline Upper & 9 & 17.6 \\
\hline Upper middle & 27 & 52.9 \\
\hline Lower middle & 13 & 25.4 \\
\hline Upper lower & 2 & 3.9 \\
\hline Lower & 0 & 0 \\
\hline
\end{tabular}

Clinical Profile: The most common presenting symptom was hyperactivity $(65 \%)$ in both genders, followed by behavioral issues $(38.5 \%)$, inattention (31.5\%), poor scholastic performance $(23.5 \%)$, and poor memory (17.6\%). Gender wise stratification showed more girls (43\%) had inattention as compared to boys (30\%) whereas more boys (66\%) presented with hyperactivity. Also, it was seen that behavioral problems as presenting complaints were seen significantly more in boys than girls ( $P$-value: 0.04).

$10 \%$ of children had a positive family history (1st or 2nd-degree relative) of neuropsychiatric illness. There were $23.5 \%$ of children who had a history of developmental delay in the early years (Table 2 and Table 3).

Functional Profile: Inattention was predominant among the sample ( $88 \%$ ) in this study with around $63 \%$ having a severe level. Severe hyperactivity was seen in $59 \%$ of children. The problem in Executive functioning $(72.5 \%)$ and learning problems $(66.6 \%)$ were seen in the majority of children and around $65 \%$ of children had severe levels of aggression. Around $53 \%$ of children had an average intelligence (IQ 90-110), 35\% had borderline IQ scores (70-89), whereas $12 \%$ had an above-average IQ (>110).

Age-wise distribution showed that borderline IQ (70-89) was seen in $61.5 \%$ of children between 9 12 years as compared to $24 \%$ in $6-8$ years age group ( $P$-value 0.01 ). Social and adaptive skills as assessed by VSMS were average in around $66.6 \%$ children. It was noticed that girls had a lower Social quotient as compared to boys of the same age ( $P$ value 0.01). Also, it was seen that a higher age group i.e. 9-12 years had a better Social Quotient as compared to the younger age group ( $P$-value 0.037) (Table 4 and Table 5).

Table-2: Clinical profile of children.

\begin{tabular}{|c|c|c|c|c|c|c|}
\hline Characteristics & Boys $(N=44)$ & Girls $(N-7)$ & p-value & $6-8$ years $(N=37)$ & $9-12$ years $(N=14)$ & p-value \\
\hline \multicolumn{6}{|c|}{ H/o developmental delay } & \multirow{3}{*}{0.715} \\
\hline No & $34(77.3 \%)$ & $5(71.4 \%)$ & 0.735 & $29(78.4 \%)$ & $10(71.4 \%)$ & \\
\hline Yes & $10(22.7 \%)$ & $2(28.6 \%)$ & & $8(21.6 \%)$ & $4(28.6 \%)$ & \\
\hline \multicolumn{6}{|c|}{ F/H/O Neuropsychiatric illness } & \multirow{3}{*}{0.694} \\
\hline Yes & $5(11.4 \%)$ & $0(0 \%)$ & 0.348 & $33(89.2 \%)$ & $1(7.1 \%)$ & \\
\hline No & $39(88.6 \%)$ & $7(100 \%)$ & & $4(10.8 \%)$ & $13(92.9 \%)$ & \\
\hline \multicolumn{6}{|l|}{ Underweight } & \multirow{3}{*}{0.419} \\
\hline No & $38(86.4 \%)$ & $5(71.4 \%)$ & 0.300 & $30(81.1 \%)$ & $13(92.9 \%)$ & \\
\hline Yes & $6(13.6 \%)$ & $2(28.6 \%)$ & & $7(18.9 \%)$ & $1(7.1 \%)$ & \\
\hline
\end{tabular}


Gupta A. et al: Clinical and functional profile of 6-12-year-old children

\begin{tabular}{|l|l|l|l|l|l|l|}
\hline \multicolumn{2}{|l|}{ Stunted } & \multicolumn{3}{l|}{$\mid$} \\
\hline No & $36(81.8 \%)$ & $7(100.0 \%)$ & 0.579 & $33(89.2 \%)$ & $10(71.4 \%)$ & 0.192 \\
\hline Yes & $8(18.2 \%)$ & 0 & & $4(10.8 \%)$ & $4(28.6 \%)$ & \\
\hline
\end{tabular}

\section{Table-3: Presenting symptoms.}

\begin{tabular}{|c|c|c|c|c|c|c|}
\hline \multicolumn{7}{|c|}{ Presenting symptoms } \\
\hline \multicolumn{6}{|c|}{ Hyperactivity } & \multirow{3}{*}{0.204} \\
\hline No & $15(34.1 \%)$ & $3(42.9 \%)$ & 0.689 & $11(29.7 \%)$ & $7(50.0 \%)$ & \\
\hline Yes & $29(65.9 \%)$ & $4(57.1 \%)$ & & $26(70.3 \%)$ & $7(50.0 \%)$ & \\
\hline \multicolumn{6}{|c|}{ Inattention } & \multirow{3}{*}{0.503} \\
\hline No & $31(70.5 \%)$ & $4(57.1 \%)$ & 0.664 & $24(64.9 \%)$ & $11(78.6 \%)$ & \\
\hline Yes & $13(29.5 \%)$ & $3(42.9 \%)$ & & $13(35.1 \%)$ & $3(21.4 \%)$ & \\
\hline Beh & oral Issues & & & & & \multirow{3}{*}{0.824} \\
\hline No & $27(61.4 \%)$ & $7(100.0 \%)$ & 0.044 & $25(67.6 \%)$ & $9(64.3 \%)$ & \\
\hline Yes & $17(38.6 \%)$ & 0 & & $12(32.4 \%)$ & $5(35.7 \%)$ & \\
\hline \multicolumn{6}{|c|}{ Poor Scholastic performance } & \multirow{3}{*}{0.715} \\
\hline No & $34(77.3 \%)$ & $5(71.4 \%)$ & 0.662 & $29(78.4 \%)$ & $10(71.4 \%)$ & \\
\hline Yes & $10(22.7 \%)$ & $2(28.6 \%)$ & & $8(21.6 \%)$ & $4(28.6 \%)$ & \\
\hline \multicolumn{6}{|c|}{ Poor Memory } & \multirow{3}{*}{0.699} \\
\hline No & $36(81.8 \%)$ & $6(85.7 \%)$ & 0.802 & $30(81.1 \%)$ & $12(85.7 \%)$ & \\
\hline Yes & $8(18.2 \%)$ & $1(14.3 \%)$ & & $7(18.9 \%)$ & $2(14.3 \%)$ & \\
\hline
\end{tabular}

Table-4: Functional Profile of children.

\begin{tabular}{|c|c|c|c|c|c|c|}
\hline \multirow[t]{2}{*}{ Functional status } & \multicolumn{2}{|c|}{ Gender } & \multirow[t]{2}{*}{ P-value } & \multicolumn{2}{|r|}{$\overline{\text { Age }}$} & \multirow[t]{2}{*}{ P-value } \\
\hline & Male & Female & & $6-8$ years $(N=37)$ & $9-12$ years $(N=14)$ & \\
\hline \multicolumn{6}{|l|}{ Problems in Peer Relation } & \multirow{4}{*}{0.461} \\
\hline$<60$ (Normal) & $21(47.7 \%)$ & $1(14.3 \%)$ & & $14(37.8 \%)$ & $8(57.1 \%)$ & \\
\hline 60-69 (Mild-moderate) & $9(20.5 \%)$ & $1(14.3 \%)$ & 0.121 & $8(21.6 \%)$ & $2(14.3 \%)$ & \\
\hline$>=70$ (severe & $14(31.8 \%)$ & $5(71.4 \%)$ & & $15(40.5 \%)$ & $4(28.6 \%)$ & \\
\hline \multicolumn{6}{|l|}{ Inattention } & \multirow{4}{*}{0.807} \\
\hline$<60$ (Normal) & $5(11.4 \%)$ & $1(14.3 \%)$ & & $5(13.5 \%)$ & $1(7.1 \%)$ & \\
\hline 60-69 (Mild-moderate) & $10(22.7 \%)$ & $3(42.9 \%)$ & 0.469 & $9(24.3 \%)$ & $4(28.6 \%)$ & \\
\hline$>=70$ (severe & $29(65.9 \%)$ & $3(42.9 \%)$ & & $23(62.2 \%)$ & $9(64.3 \%)$ & \\
\hline \multicolumn{6}{|l|}{ Hyperactivity } & \multirow{4}{*}{0.360} \\
\hline$<60$ (Normal) & $5(11.4 \%)$ & 0 & & $3(8.1 \%)$ & $2(14.3 \%)$ & \\
\hline 60-69 (Mild-moderate) & $15(34.1 \%)$ & $1(14.3 \%)$ & 0.280 & $10(27.0 \%)$ & $6(42.9 \%)$ & \\
\hline$>=70$ (severe & $24(54.5 \%)$ & $6(85.7 \%)$ & & $24(64.9 \%)$ & $6(42.9 \%)$ & \\
\hline \multicolumn{6}{|l|}{ Learning problem } & \multirow{4}{*}{0.278} \\
\hline$<60$ (Normal) & $16(36.4)$ & $1(14.3 \%)$ & & $14(37.8 \%)$ & $3(21.4 \%)$ & \\
\hline 60-69 (Mild-moderate) & $14(31.8 \%)$ & $3(42.9 \%)$ & 0.516 & $10(27.0 \%)$ & $7(50.0 \%)$ & \\
\hline$>=70$ (severe) & $14(31.8 \%)$ & $3(42.9 \%)$ & & $13(35.1 \%)$ & $4(28.6 \%)$ & \\
\hline
\end{tabular}

Table-5: Functional Profile of children with emphasis on executive functioning, aggression. IQ and SQ.

\begin{tabular}{|l|l|l|l|l|l|}
\hline Executive functioning & $12(27.3 \%)$ & $2(28.6 \%)$ & 0.158 & $9(24.3 \%)$ & $5(35.7 \%)$ \\
\hline$<60$ (Normal) & $21(47.7 \%)$ & $1(14.3 \%)$ & & $14(37.8 \%)$ & $8(57.1 \%)$ \\
\hline $60-69$ (Mild-moderate) & $11(25.0 \%)$ & $4(57.1 \%)$ & & $14(37.8 \%)$ & $1(7.1 \%)$ \\
\hline$>=70$ (severe) & & & 0.912 & & \\
\hline Aggression & $7(15.9 \%)$ & $1(14.3 \%)$ & & $7(18.9 \%)$ & $1(7.1 \%)$ \\
\hline$<60$ (Normal) & $9(20.5 \%)$ & $1(14.3 \%)$ & & $6(16.2 \%)$ & $4(28.6 \%)$ \\
\hline $60-69$ (Mild-moderate) & $28(63.6 \%)$ & $5(71.4 \%)$ & & $24(64.9 \%)$ & $9(64.3 \%)$ \\
\hline$>=70$ (severe) & & & & 0.430 \\
\hline
\end{tabular}


Gupta A. et al: Clinical and functional profile of 6-12-year-old children

\begin{tabular}{|c|c|c|c|c|c|c|}
\hline \multicolumn{6}{|l|}{ IQ } & \multirow{5}{*}{0.000} \\
\hline$<70$ & 0 & 0 & 0.541 & 0 & 0 & \\
\hline $70-89$ & $15(34.9 \%)$ & $2(28.6 \%)$ & & $9(24.3 \%)$ & $8(61.5 \%)$ & \\
\hline $90-110$ & $23(53.5 \%)$ & $5(71.4 \%)$ & & $27(73 . \%)$ & $1(7.7 \%)$ & \\
\hline$>110$ & $5(11.6 \%)$ & 0 & & $1(2.7 \%)$ & $4(30.8 \%)$ & \\
\hline \multicolumn{6}{|l|}{ SQ } & \multirow{5}{*}{0.037} \\
\hline$<70$ & 0 & 0 & & 0 & 0 & \\
\hline $70-89$ & $3(6.8 \%)$ & $3(42.9 \%)$ & 0.014 & $6(16.2 \%)$ & 0 & \\
\hline $90-110$ & $30(68 \%)$ & $4(57.1 \%)$ & 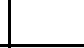 & $26(70.3 \%)$ & $8(57.1 \%)$ & \\
\hline$>110$ & $11(25 \%)$ & 0 & & $5(13.5 \%)$ & $6(42.9 \%)$ & \\
\hline
\end{tabular}

Risk Factor Association: It was observed that low Social quotient was a risk factor for Inattention ( $P$ value 0.027) and Learning Problem (P-value 0.00). Lower the social quotient higher the level of Inattention and Learning problems was seen in children with ADHD. Also, lower maternal education was seen to be significantly associated with Inattention (P-value 0.048) and learning problems in children with ADHD (P-value 0.020). Children living in nuclear families had higher levels of Aggression (P-value 0.039).

\section{Discussion}

In the present study, the prevalence of ADHD among primary school children referred to tertiary care centers with various issues was found to be $12.7 \%$. Male preponderance was seen, with male to female ratio of $6: 1$. This finding was consistent with that of previous studies where gender difference with the ratios ranging from 10:1 in the clinically referred sample to $3: 1$ in a community sample was seen [6]. In the present study, the majority of children were from upper and upper-middle-class socioeconomic status according to the Modified Kuppuswamy scale [7]. It was also observed that all parents were educated with most having higher secondary/ graduate or post-graduate education. This finding however is inconsistent with previous studies and systematic review that shows a strong association of low socioeconomic status and lower parental education with a higher risk of ADHD [8]. Higher parental education could be due to the overall high literacy rate in Kerala [9]. About 2/3rd of the sample were residents of rural areas. The peak age at presentation with ADHD was observed to be 6-8 years, which was consistent with several previous studies that have identified a higher presentation of ADHD among children less than 7 years [10]. It was seen that the most common clinical presentation of these children was
Hyperactivity-impulsivity followed by Behavioral issues and inattention. More boys presented with hyperactivity and girls with inattention. This finding is consistent with various studies and guidelines that mention the presence of Hyperactivity as the most common symptom of ADHD in young children and boys having more hyperactivity as presenting complaints [11].

An important statistically significant finding was that none of the girls presented with behavioral issues as compared to boys. This finding could be an indicator that boys with ADHD have more features of oppositional behavior compared to girls. Around $10 \%$ of children had a positive family history of a neuropsychiatric disorder, this finding, though statistically insignificant in the present study is consistent with several previous studies that show a strong familial nature of the disorder $[12,13]$.

On Conner's Rating scale, it was seen that Inattention and Hyperactivity- Impulsivity were significantly high in the majority of children. Also, all girls had significant hyperactivity even if it was not the presenting complaint. This finding has importance, as hyperactivity might not be as uncommon as thought to be in girls with ADHD. However, more studies are required to establish this finding. Most children also had severe levels of concern in executive functioning, learning, and aggression. In the present study, it was seen that more children presenting at a later age had lower IQ scores as compared to those presenting at a younger age which could be the result of untreated ADHD.

Another explanation for this finding could be that children with ADHD and a comorbid lower IQ have more scholastic issues than those who have ADHD normal IQ. These children with normal IQ and ADHD might be missed by parents or teachers due to their average school performance and may not be reported at all. However, the finding is important as 
It emphasizes the need for early diagnosis. Since it is mentioned in various textbooks that IQ usually stabilizes by $14-15$ years of age, the finding is suggestive that early detection and timely intervention may help in improving later functional status and IQ scores [14]. Another important observation in the study was a negative association between Social Quotient and Inattention and Learning problems.

Lower social quotient was a significant risk factor for these issues. This also emphasizes the importance of early detection, which will help in the early institution of therapies and a hence overall improvement in the Social quotient of children with ADHD. Also, it was seen that boys had a better social quotient than girls which was statistically significant. Owens et al in their study had seen that only $16 \%$ of girls with ADHD had normal social skills as compared to $86 \%$ of girls without ADHD [15]. This observation about girls with poorer social skills than boys with ADHD might be an incidental finding in this study and more studies are needed to establish this assumption. Also, better SQ in older age groups could be related to the natural process of maturation, which is related to age.

\section{Limitations}

Only the parent rating scale was used. This could have resulted in biased results either due to underreporting or over-reporting of the symptoms by the parents. However, this limitation could be explained by the fact that the data collected was from single contact i.e. when the child first presented to the center. It is therefore important to include the teacher rating scale also, as it can help in understanding the child's issues across two different settings at the outset and will remove parental bias in reporting.

\section{Conclusion}

ADHD is a neurodevelopmental disorder that can result in academic, social, and individual consequences. Many children are identified with the problem when they start going to formal school and when the teacher notices the child be different from peers. However, till then there might be a considerable loss of critical period of neurodevelopment which may adversely affect a child's wellbeing over the long term and hence timely detection of this issue can help the child to achieve his/ her maximum potential.

\section{What does the study add to the existing knowledge}

The present study addresses some important aspects regarding ADHD in primary school children. The overall course and presentation of childhood ADHD show a consistent and similar clinical pattern between various ages especially 6-12 years, therefore vigilance is advised at all ages and levels.

- It is useful to consider the functional profile of all children with ADHD at the outset of diagnosis. By quantifying their difficulties in various domains and identifying problem behaviors at the beginning and planning

- the intervention accordingly will help in targeting these issues specifically and hence improving the long-term outcome of these children.

- It also highlights the need for early diagnosis of ADHD and early intervention, which can improve the functionality and cognitive performance of these children. However, for this, the prerequisite is that school teachers and parents need to be more sensitized and informed and this change could be brought about by Government campaigns.

\section{Author's contribution}

Dr. Arpita Gupta: Conceptualized the study, collected the data, and drafted the manuscript.

Dr. Babu George: Gave permission, supervised behavioral and cognitive assessments.

Dr. M.K.C Nair: Supervised clinical assessments and data analysis.

Dr. ML Leena: Data Analysis.

Dr. Deepa Bhaskaran: Helped in drafting and editing of the manuscript.

\section{Reference}

01. National Census 2011. Literacy in India. Accessed from internet on 28/12/2018. Available from: https://www. census2011.co.in/literacy.php [Crossref]

02. Singhi $P$, Malhi P. Spectrum of Attention deficit hyperactivity disorder in school-aged children. Indian Pediatr. 2000;37(11)1256-1260.

[Crossref] 
03. Singh A, Yeh CJ, Verma N, Das AK. Overview of attention deficit hyperactivity disorder in young children. Health Psychol Res. 2015;3(2).

doi: 10.4081/hpr.2015.2115 [Crossref]

04. Diagnostic and Statistical Manual of Mental Disorders. American Psychiatric association. Special ed- New Delhi- CBS Publishers and distributors PVT LTD. 2017;59-65.

[Crossref]

05. Sayal K, Prasad V, Daley D, Ford T, Coghill D. ADHD in children and young people- prevalence, care pathways, and service provision. Lancet Psychiat. 2018;5(2)175-186.

doi: $\quad 10.1016 /$ S2215-0366(17)30167-0 [Crossref]

06. Fayyad J, De Graaf R, Kessler R, Alonso J, Angermeyer $M$, Demyttenaere $K$, et al. Crossnational prevalence and correlates of adult attention-deficit hyperactivity disorder. $\mathrm{Br}$ J Psychiatry. 2007;190(5)402-409.

doi: 10.1192/bjp.bp.106.034389 [Crossref]

07. Jyothsna A, Anuja S Panicker. Prevalence of attention deficit hyperactivity disorder in primary school children. Indian J Psychiatry. 2013;55(4)338-342.

Available from : [Article] [Crossref]

08. Biederman J, Mick E, Faraone SV, Braaten E, Doyle $A$, Spencer $T$, et al. Influence of gender on attention deficit hyperactivity disorder in children referred to a psychiatric clinic. Am J Psychiatry. 2002;159(1)36-42.

doi: 10.1176/appi.ajp.159.1.36 [Crossref]

09. Russel AE, Ford T, Williams R, Williams R, Russel $G$. The association between Socioeconomic Disadvantage and Attention Deficit Hyperactivity Disorder- A Systematic Review. Child Psychiatry Hum Dev. 2016;47(3)440-458.

doi: $\quad 10.1007 / \mathrm{s} 10578-015-0578-3 \quad$ [Crossref]
10. Tulika S, Sanju S, Seetharamiah N. Socioeconomic status scales updated for 2017. Int J Res Med Sci. 2017;5(7)3264-3267.

doi: $10.18203 / 2320-6012 . i j r m s 20173029$ [Crossref]

11. Faraone SV, Doyle AE, Mick E, Biederman J. Meta-analysis of association between the 7repeat allele of the dopamine receptor gene and attention deficit hyperactivity disorder. Am J Psychiatry. 200;158(7)1052-1057.

doi: $\quad 10.1176 /$ appi.ajp.158.7.1052 [Crossref]

12. Faraone SV, Tsuang MT. Methods in psychiatric genetics- Tohen M, Tsuang MT, Zaner GE, editors, Textbook in psychiatric epidemiology. 2nd ed, New York- John Wiley and Sons. 1995:81-134.

[Crossref]

13. Illingworth's. The Development of the Infant and Young Child- Normal and Abnormal, MKC Nair, Paul Russell, editors. 10th ed; New DelhiElsevier Health Sciences; reprinted. 2017;139140.

[Crossref]

14. Owens EB, Hinshaw SP, Lee SS, Lahey BB. Few girls with childhood Attention deficit Hyperactivity disorder show positive adjustment during adolescence. J Clin Child Adolescen Psychol. 2009;38(1)132-143.

doi: $10.1080 / 15374410802575313 \quad$ [Crossref]

15. Wolraich M, Brown L, Brown RT, DuPaul G, Earls $M$, Feldman $H M$, et al. Subcommittee on Attention Deficit Hyperactivity Disorder; Steering Committee on Quality Improvement and Management, ADHD- clinical practice guideline for the diagnosis, evaluation, and treatment of attention-deficit/hyperactivity disorder in children and adolescents. Pediatr. $2011 ; 128(5) 1007-1022$.

doi: 10.1542/peds.2011-2654 [Crossref] 